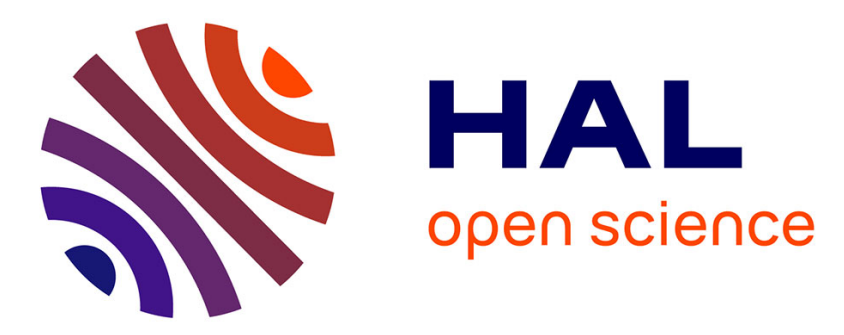

\title{
COMPARATIVE STUDY OF THE COOLING OF A HOT TEMPERATURE SURFACE USING SPRAYS AND LIQUID JET
}

Alexandre Labergue, Thomas Aiguier, Michel Gradeck, Fabrice Lemoine

\section{- To cite this version:}

Alexandre Labergue, Thomas Aiguier, Michel Gradeck, Fabrice Lemoine. COMPARATIVE STUDY OF THE COOLING OF A HOT TEMPERATURE SURFACE USING SPRAYS AND LIQUID JET. 15th International Heat Transfer Conference (IHTC-15), Aug 2014, Kyoto, Japan. pp.2415-2429, 10.1615/IHTC15.evp.009287 . hal-01579529

\section{HAL Id: hal-01579529 \\ https://hal.science/hal-01579529}

Submitted on 1 Sep 2017

HAL is a multi-disciplinary open access archive for the deposit and dissemination of scientific research documents, whether they are published or not. The documents may come from teaching and research institutions in France or abroad, or from public or private research centers.
L'archive ouverte pluridisciplinaire HAL, est destinée au dépôt et à la diffusion de documents scientifiques de niveau recherche, publiés ou non, émanant des établissements d'enseignement et de recherche français ou étrangers, des laboratoires publics ou privés. 


\title{
COMPARATIVE STUDY OF THE COOLING OF A HOT TEMPERATURE SURFACE USING SPRAYS AND LIQUID JET
}

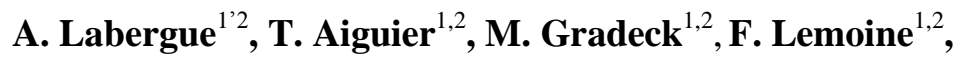 \\ 1: Université de Lorraine, LEMTA, UMR 7563, Vandoeuvre-lès-Nancy, France \\ 2: CNRS, LEMTA, UMR 7563, Vandoeuvre-lès-Nancy, France
}

\begin{abstract}
An experimental test-rig was designed to study the cooling of hot surfaces under semi-industrials conditions. Two cooling methods were compared: liquid jet and full cone sprays. The wall is a $175 \mathrm{~mm}$ diameter nickel disk heated by electromagnetic induction up to $800^{\circ} \mathrm{C}$. The heat removed during the cooling phase was investigated with the use of infrared thermography while the droplet properties, in the case of sprays, were characterized simultaneously with a Phase Doppler system. In the case of spray cooling, the Phase Doppler technique was mainly applied to study the statiscal properties of the droplets in the vicinity of the heated surface. The influence of the liquid mass flux distribution as well as the droplets properties on the cooling are studied by using five different spray nozzles. The liquid mass flux distribution is also measured with the help of patternator. The main results show that even if higher heat flux can be removed with the liquid jet the efficiency cooling is poor because of its non uniformity. When spray cooling is considered, the results are in qualitative agreement with previous studies performed in similar conditions.
\end{abstract}

KEY WORDS: Spray cooling, spray heat transfer, infrared thermography, inverse conduction problem, Phase Doppler Analysis.

\section{INTRODUCTION}

The use of water for cooling of hot surfaces in industry is unavoidable when high heat flux dissipation is required. Nuclear safety issues or the thermal processing of alloys in steel industry are good examples. Cooling processes include pool boiling, impingement of liquid jets or sprays. Pool boiling and liquid jets provide high dissipation rates but they have generally failed to ensure uniform and controlled cooling.

In steel industry, cooling by means of impinging water jets is still widely used. However, the spatial uniformity of heat flux removed from the surface cannot be achieved using impinging water jets and thus the homogeneity of the metallurgical steel phase cannot meet the quality standards. The use of sprays seems attractive for several reasons: a better spatial uniformity of the cooling can be achieved associated lower water consumption for the same efficiency in the obtained heat transfer, thus leading to energy saving. The experimental studies devoted to water spray cooling cover a wide range of cooling conditions [1-7]. Several kinds of sprays are employed, such as mono-sized sprays [1;2] or polydisperse sprays [3-7]. Moreover, several categories of nozzles are available to generate various sprays with different geometries and liquid densities: full cone, hollow cone, flat fan or air-mist nozzles. However, only few authors have performed comparisons between these different systems [3]. Another key issue is the scale under which the experiments are conducted, either laboratory scale or industrial scale in term of liquid flowrate. In steel processing industry, the surface temperatures are generally above the Leidenfrost point and high liquid mass flux are required, which involved large-sized droplets. For instance, Al-Ahmadi [3] and Yao [7] estimated the heat flux removed by sprays under conditions that are close to industry operations (droplet diameters up to $25 \mathrm{~mm}$ and liquid mass flux up to $30 \mathrm{~kg} / \mathrm{m}^{2} / \mathrm{s}$ respectively). However, the hydrodynamic characteristics of the droplet interaction with the heated surface were not investigated.

Very often, thermocouples, combined to an inverse conduction method, and Phase Doppler system (PDA) are combined to characterize respectively the heat flux removed from the droplet surface and the droplet 
properties (velocity and diameter distributions) [8-9]. More recently, infrared thermography was also applied to estimate the heat flux extracted from a heated wall by water cooling [10-11]. But these latter concern mainly liquid jets, single droplets or monodisperse droplet streams. Jia and Qiu [8] achieved to detect both incoming and outcoming droplets in the case of a low liquid mass flux value $\left(1.20 \mathrm{~kg} / \mathrm{m}^{2} / \mathrm{s}\right.$ in maximum). Puschmann et al. [12] have used a 2D-PDA system and infrared measures to characterize simultaneously the droplet properties and the heat flux removed by sprays having a maximum liquid mass flux of about 5 $\mathrm{kg} / \mathrm{m}^{2} / \mathrm{s}$. Nevertheless, the hydrodynamic characteristics of the impinging droplets were not studied.

Therefore, the present work aims to compare the cooling efficiency of several full cone sprays and of a continuous liquid jet. An experimental set-up was designed in order to operate close industrials conditions: in the case of sprays, both heat flux and characteristics of the droplets interacting with the droplet surface were characterized simultaneously. In the case of a liquid jet, only the cooling efficiency was determined. The surface to be cooled is a circular disk made of nickel, which is previously heated above the Leidenfrost temperature. A 2D-PDA system was used in the front face of the plate and an infrared camera is used to measure the temperature field on the opposite surface. An inverse conduction model is used to estimate the removed heat flux.

\section{SPRAYS FACILITIES}

An experimental test rig, sketched in Fig. 1, was designed in order to work under conditions as closed as possible as industrial conditions.

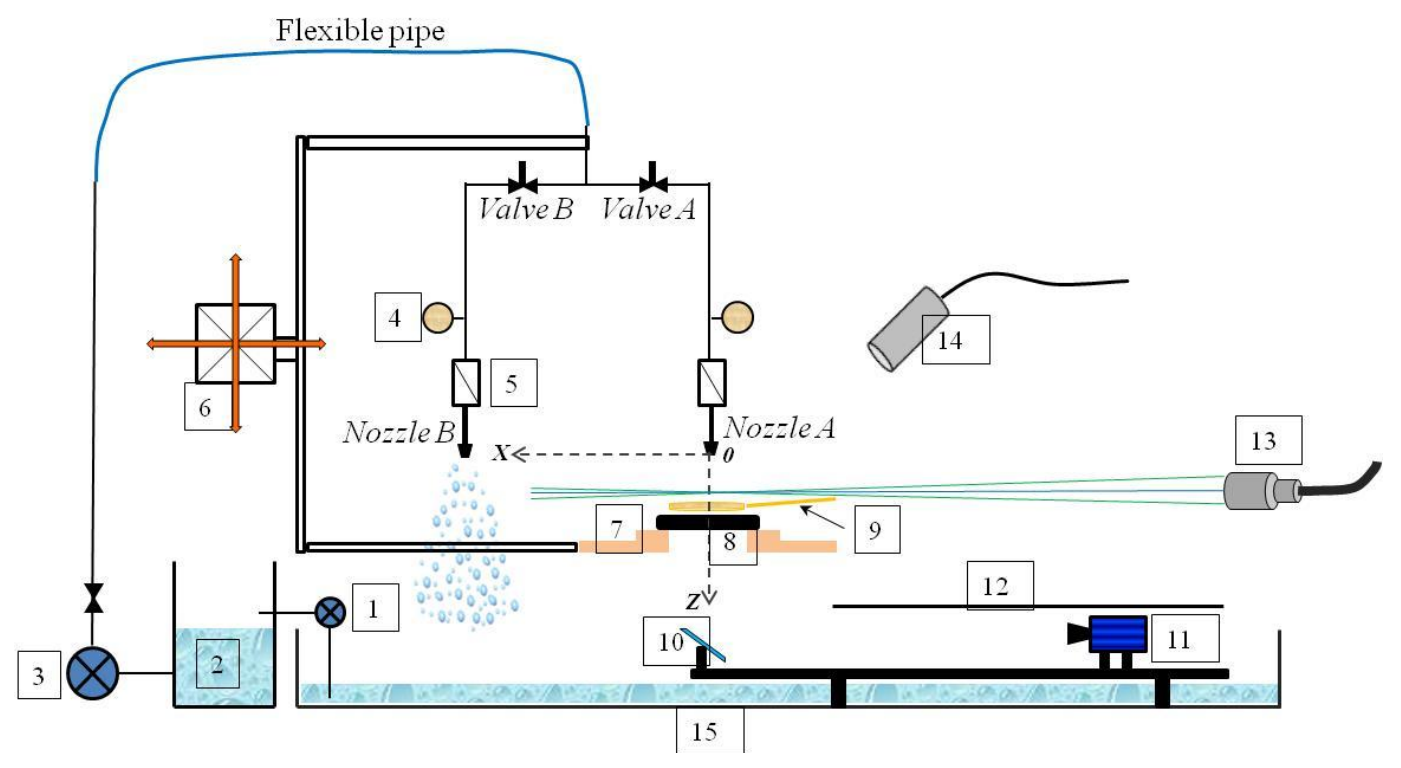

Fig. 1 Side view (i.e. X-Z plane) of the test rig. 1 - Pump1; 2 - Water tank; 3 - Pump2; 4 - Manometer; 5 Flowmeter; 6 -3D traverse system; 7 - insulation part (quartz); 8 - nickel disk; 9 - retractable inductor; 10 - mirror; 11 - infrared camera; 12 - IR camera protective cover; 13 - laser probe; 14 - PDA receiver; 15 main tank for water collecting.

As the spreading of the impact occurs on a large area, a $3 \times 4 \times 0.30 \mathrm{~m}^{3}$ tank (15) was made where water remains permanently. So that, the cooling water from a tank supplies the nozzle by means of a closed looped circuit. A first pump (1) transfers the water from the main tank (15) up to a second tank (2). Then, a centrifugal regulated pump (3) ensures the circulation of the liquid at the desired operating parameters (i.e. flow rate and injection pressure controlled respectively with a manometer (4) and a flowmeter (5)). The cooling of a hot surface with water is basically a transient phenomenon. Here, an experiment is divided into two steps: a heating phase of the surface to be cooled (the spray is not flowing) and a cooling phase that consists in applying the spray. However, 
the time to establish the spray flow is not negligible compared to the cooling time. This time could be reduced by maintaining the centrifugal pump switched at the same operating point. Therefore, a second nozzle is used so that during the heating phase, a second spray flows directly towards the main tank. Two valves (Valve A and B) allow switching from a spray to the other one.

Table 1 Description of the five sprays and of liquid jet used with their experimental operating conditions.

\begin{tabular}{l|c|c|c|c|c}
\hline - Sprays & $\begin{array}{c}\text { Spray angle } \\
\left({ }^{\circ}\right)\end{array}$ & $\begin{array}{c}\text { Flow } \\
\text { rate } \\
(1 / \mathrm{mn})\end{array}$ & $\begin{array}{c}\text { Injection } \\
\text { Pressure } \\
(\text { bar })\end{array}$ & $\begin{array}{c}\text { Nozzle-disk } \\
\text { distance, Z- } \\
\text { direction } \\
(\mathrm{mm})\end{array}$ & $\begin{array}{c}\text { Injection } \\
\text { temperature } \\
T_{l}\left({ }^{\circ} \mathrm{C}\right)\end{array}$ \\
\hline Nozzle 1 & 45 & 6.7 & 7 & 250 & 19 \\
\hline Nozzle 2 & 45 & 5.5 & 7 & 250 & 19 \\
\hline Nozzle 3 & 45 & 6.7 & 3.7 & 250 & 19 \\
\hline Nozzle 4 & 60 & 6.7 & 7 & 160 & 19 \\
\hline Nozzle 5 & 60.7 & 3.7 & 160 & 19 \\
\hline & $\begin{array}{c}\text { Jet diameter } \\
(\mathrm{mm})\end{array}$ & $\begin{array}{c}\text { Flow rate } \\
(\mathrm{l} / \mathrm{mn})\end{array}$ & & $\begin{array}{c}\text { Nozzle-disk } \\
\text { distance, Z- } \\
\text { direction }(\mathrm{mm})\end{array}$ & \\
\hline & 9 & 6.7 & & 250 & 19 \\
\hline
\end{tabular}

The disk (8) is made out of nickel (Radius $R=87.5 \mathrm{~mm}$ and thickness $e=5 \mathrm{~mm}$ ) because the properties of this metal are very close to those of steel. The disk is positioned horizontally below the nozzle A so that the disk center is aligned with the nozzle axis. The disk is placed on a ring made of an insulating material (7). The disk and both nozzles with their respective holders are fixed together on a 3D-traverse system (6). The origin of the $X-Y-Z$ axis is taken at the exit nozzle A. The $Z$-axis direction corresponds to the spray motion. Above, the upper surface of the disk (designated by front face), measurements of the droplet size and velocity are performed with a phase Doppler system (PDA) (Items (14) and (13) in Fig. 1). The temperature of the opposite wall (designated by rear face) is measured by an infrared camera (11) through a $45^{\circ}$ mirror (10). Both the mirror and the camera are protected against expelled water with the insulating part (7) and a protective cover (12) respectively. Heating of the disk is realized by an electromagnetic induction system (Power Supply $12 \mathrm{~kW}$; Five-Celes ${ }^{\circledR}$ ). A retractable inductor (9) is placed just above the front face of the plate during the heating phase and is removed before the cooling with the sprays.

One of the objectives of the present work is to test several droplet size and velocity distributions as well as different liquid mass flux distributions. Therefore, five Lechler ${ }^{\circledR}$ nozzles (numbered from 1 to 5) leading to full cone sprays are used. The differences between these sprays concern their flow rate for a similar injection pressure and their cone angle value. Nozzles 1,2 and 3 present a cone angle of $45^{\circ}$, while nozzles 4 and 5 have a cone angle of $60^{\circ}$. Thus, to ensure that the spray covers all the surface area, the elevation $Z$ (distance between the exit nozzle and the front face of the disk) is adapted according to the disk radius and the value of the spray angle. Table 1 summarizes the value of each of the parameter for the five nozzles. Fig. 3 presents typical droplet size distributions measured with the PDA system for the five nozzles in the section center $(X=Y=0)$ and at the $Z$ elevation from the nozzles according values given by Table 1 . All distributions peak at the same diameter value $(d \approx 40 \mu \mathrm{m})$. Nozzle 2 and nozzle 5 have the smallest and largest droplets respectively.

When the liquid jet is used, a $9 \mathrm{~mm}$-diameter tube is used with similar operating conditions as nozzle 1, i.e. at $Z=250 \mathrm{~mm}$ above the disk center and with a flow rate of $6.71 / \mathrm{mn}$ (Table 1 ).

\section{EXPERIMENTAL DIAGNOSTICS}

\subsection{D Phase Doppler Measurements}


Droplet size and velocity were measured using a phase Doppler system (PDA). The technique was used to characterize the properties of the five free sprays in absence of the target. For that purpose, the PDA measurements volume is located at the same $Z$ elevation value as those of the front face of the disk (i.e. $Z=250 \mathrm{~mm}$ for nozzle 1,2 and 3 and $Z=140 \mathrm{~mm}$ for nozzles 4 and 5 ). The spray is moved in the $X-Y$ plane by using the 3D-traverse system in order to cover the whole section of each spray. In a second step, PDA measurements were performed to characterize impingement of the droplets on the heated surface.

The phase Doppler system is a 2D commercial classic PDA manufactured by Dantec-Dynamics ${ }^{\circledR}$. An argon ion laser, operating in multiline mode, is used to generate two wavelengths $\left(\lambda_{v}=514.5 \mathrm{~nm}\right.$ and $\left.\lambda_{v}=488 \mathrm{~nm}\right)$ in order to obtain the two overlapped laser illuminated volumes. The illuminated volume was formed by using a LDA transmitter probe (Dantec-dynamics Fiber-Flow ${ }^{\circledR}$ probe) which is aligned along the $X$-direction (label (13) in Fig. 1). The system includes a classic reception optical device and a P80 signal processor. The receiver (label (14) in Fig. 1) is operating in the first refraction mode with an off-axis angle of $60^{\circ}$. The front lens of the transmitter probe is $1200 \mathrm{~mm}$ while the focal length of the receiver is $510 \mathrm{~mm}$, leading to a maximum detectable droplet size of $327 \mu \mathrm{m}$.

In order to characterized the droplets interacting with the heated plate (incoming and outcoming droplets), the PDA probe volume has to be relatively close to the front face. But the presence of a large droplets cloud between the probe volume and the PDA receiver can strongly disturb the signal. Then, the PDA receivers as well as the beams system were inclined of an angle an angle of $45^{\circ}$ (Fig. 2). This rotation was corrected in the calculation of the two velocity components so that to obtained them the $X-Y-Z$ reference. Therefore, the components along the $Z$-axis $(w)$ and along the $Y$-axis $(v)$ were measured. With this configuration, droplets impinging the disk have positive velocities and droplets with negative velocities are considered as outcoming droplets. Table 2 gives the characteristics of the PDA optical configuration.

Table 2 Characteristics and optical configurations for the 2D PDA measurements.

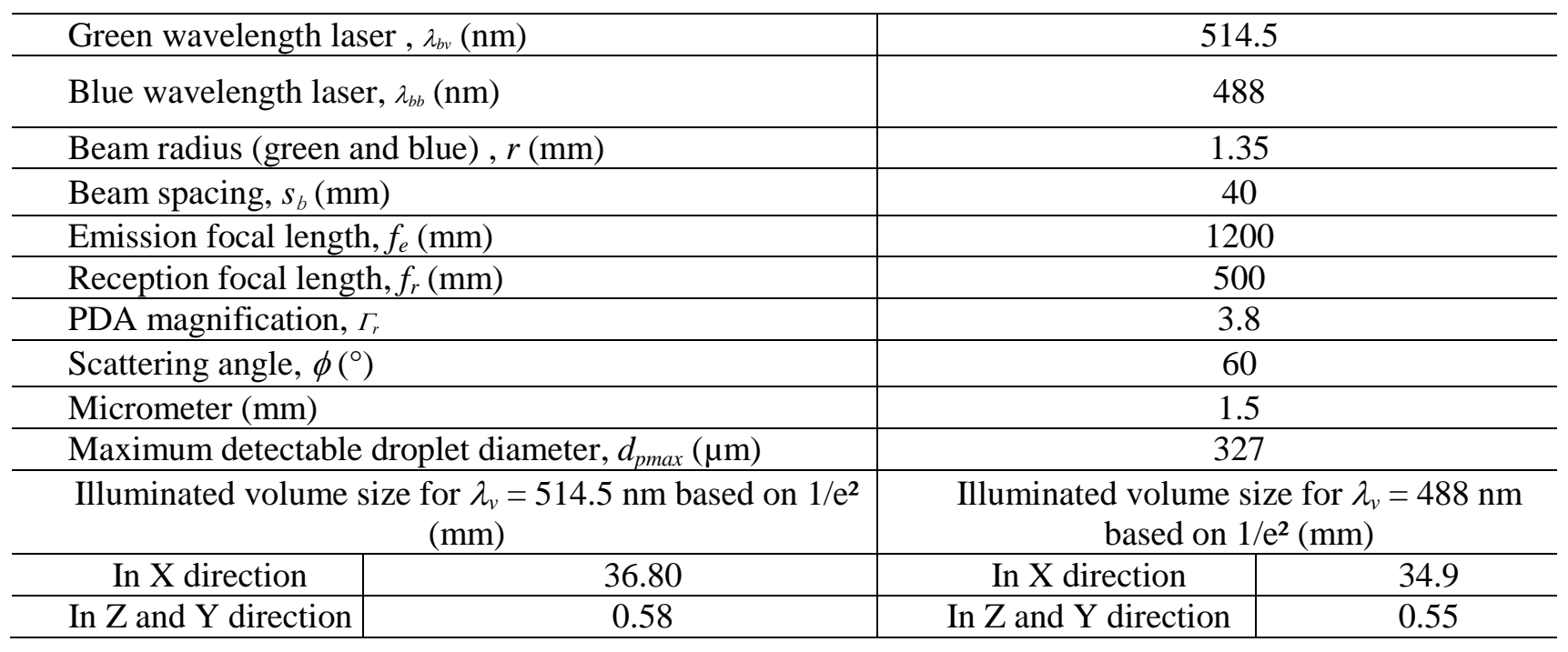



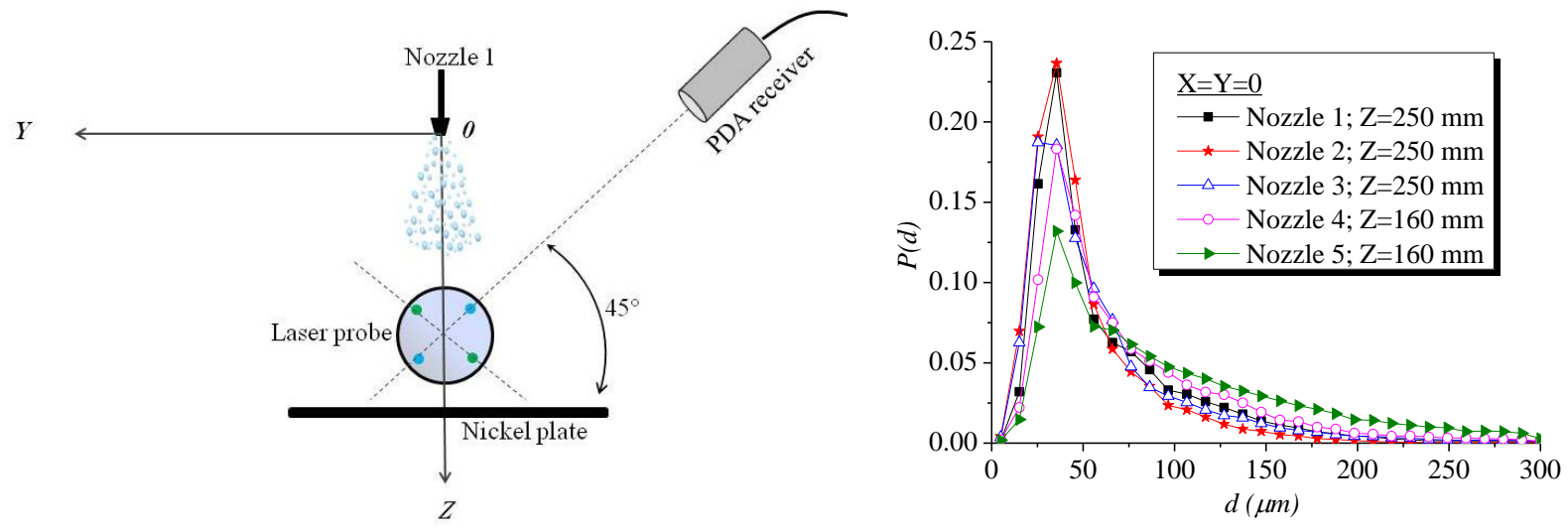

Fig. 2 Front view (i.e. Y-Z plane) of both laser and receiver probes arrangement.

Fig. 3 Typical droplet size distributions for the five studied nozzle measured without disk.

\subsection{Heat flux measurements}

Infrared thermography - The infrared camera (Cedip Jade III) is built around a focal plane array photonics detectors (InSb) working in the spectral range [3-5 $\mu \mathrm{m}]$ and it is equipped with a narrow [3.97-4.01 $\mu \mathrm{m}]$ spectral interval filter to fit with the expected experimental temperature range. It allows the measurements of up to $320 \times 240$ pixels/frame. The sampling rate depends of the phenomenon duration observed; here, the cooling phase has a typical duration of about 20 s to 30 s and the desired number of frames to store per run is about 2000. Thus, the frequency for all experiments conducted in this study is adjusted at about $60 \mathrm{~Hz}$. The calibration of the detector itself was performed with a large blackbody. Then, to accurately measure the field of temperature of the nickel disk's surface, one face of the disk (rear face) has been previously sandblasted to obtain a diffuse surface. Then, the surface has been oxidized (with $\mathrm{O}_{2}$ of air) at high temperature. The layer of obtained oxide is so thin and so stable that it has no effect on heat transfer and guaranties a stable radiation property. The value of total measured emissivity is $\varepsilon_{r}=0.64$. A last measurement using a thermocouple is required for calibrate the whole measurement chain (i.e. to account for the mirror and environment); for such calibration, a thermocouple is inserted at the disk centerline in the rear face in order to have a reference temperature: the disk is firstly heated up to $800^{\circ} \mathrm{C}$ then the infrared signal is measured simultaneously with the thermocouple signal while the disk cooled down naturally (without additional cooling provided by spray or water jet).

Inverse heat conduction prolem - Knowing the temperature field at the rear face, an inverse heat conduction model is used to estimate both the heat flux due to the spray or jet cooling and to determine the temperature on the front face. The 3D real internal conduction problem is reduced to a $2 \mathrm{D}$ one by angular averaging. So that only an estimate of the averaged value of the heat flux $q{ }^{\prime}$ spray $(r, t)$ is available. Then, the $2 \mathrm{D}$ internal transient conduction reduced problem within the nickel circular disk is solved assuming some hypothesis: constant nickel thermophysical properties, no conduction losses due to the disk holder and no losses at the edge of the disk. A full description of the model is available in papers $[10 ; 13 ; 15]$. The reduced problem to be solved is thus described by the following equation associated with the initial and boundary conditions:

$$
\begin{gathered}
\frac{\partial^{2} T}{\partial r}+\frac{1}{r} \frac{\partial T}{\partial r}+\frac{\partial^{2} T}{\partial z}=\frac{1}{a} \frac{\partial T}{\partial t} \\
T=T_{\text {init }}(r) \text { at } t=0 \\
\left.k \frac{\partial T}{\partial z}\right|_{z=0}=q_{\text {spray }}^{\prime \prime}(r, t) \\
-\left.k \frac{\partial T}{\partial z}\right|_{z=e}=h_{r}(T)\left(T-T_{\infty}\right)+\varepsilon_{r} \sigma\left(T^{4}-T_{\infty}^{4}\right)
\end{gathered}
$$




$$
-\left.k \frac{\partial T}{\partial r}\right|_{r=R}=0, \text { in } r=R
$$

Laplace (time) and Hankel (space) transforms are performed so that equation (1a) can be solved :

$$
\frac{\partial \tilde{\bar{T}}_{n}^{2}}{\partial z}-\left(\alpha_{n}^{2}+\frac{p}{a}\right) \tilde{\bar{T}_{n}}=0 \text { with } u_{n} \approx n \pi+\frac{\pi}{8\left(n \pi+\frac{\pi}{4}\right)}
$$

with $\alpha_{n}=\frac{u_{n}}{R} \quad$ and $u_{n}$ solutions of $J_{1}(u)=0$. Finally, the quadrupole method [15] yields a linear relationship between the rear face temperature $(z=e)$ and the cooling heat flux $(\mathrm{z}=0)$ :

where:

$$
\tilde{\bar{T}}_{n}=\tilde{Z}_{n}(p) \tilde{\bar{q}}_{n}
$$

$$
\bar{Z}(p)=\frac{1}{\left.h_{I N F}^{E Q} \cosh (e \sqrt{p / a})+\lambda(\sqrt{p / a}) \sinh (e \sqrt{p / a})\right)} \frac{1}{p}
$$

$h_{I N F}^{E Q}$ is an equivalent heat transfer coefficient accounting for convection and radiation losses; $p$ is the Laplace parameter. Laplace inversion of equation (2) is a convolution product and can be expressed as :

$$
\tilde{T}_{n}(t)=\int_{0}^{t} e^{-a \alpha_{n}^{2}\left(t-t^{\prime}\right)} \tilde{Z}_{n}\left(t-t^{\prime}\right) \tilde{q}_{n}\left(t^{\prime}\right) d t^{\prime}
$$

Finally, the real temperature in time-space domain is obtained through the following relation :

$$
T(r, e, t)=\frac{2}{R^{2}} \sum_{n=0}^{\infty} \tilde{T}_{n}(e, t) \frac{J_{0}\left(\alpha_{n} r\right)}{J_{0}^{2}\left(\alpha_{n} R\right)}
$$

The inverse problem consists in estimating the surface heat cooling flux. In the real problem estimation, equation (4) is truncated at a finite harmonic number, $n_{\max }$. Equation (3) can be written as follows:

$$
\tilde{T}_{n}\left(t_{k}\right)=\sum_{l=1}^{k} e^{-a \alpha_{n}^{2}(k-l) \Delta t} \tilde{Z}_{n}(k-l) \tilde{q}_{l}^{n}\left(t_{l}\right) \Delta t
$$

where $\Delta t$ is the time step of the camera or a multiple and $t_{k}=k \Delta t, t_{l}=l \Delta t$. Equation (5) can be written as a linear matrix relationship:

$$
\tilde{\boldsymbol{\theta}}_{n}=\left[\begin{array}{c}
\tilde{T}_{n}\left(t_{1}\right) \\
\cdot \\
\cdot \\
\widetilde{T}_{n}\left(t_{k_{\max }}\right)
\end{array}\right]=\mathbf{S}_{k}^{n} \widetilde{\mathbf{q}}_{n}=\left[\begin{array}{cccc}
S_{11}^{n} & 0 & 0 & 0 \\
\cdot & \cdot & 0 & 0 \\
\cdot & \cdot & \cdot & 0 \\
S_{k_{\max }}^{n} & \cdot & \cdot & S_{k_{\max } k_{\max }}^{n}
\end{array}\right]\left[\begin{array}{c}
\tilde{q}_{1}^{n} \\
\cdot \\
\cdot \\
\tilde{q}_{k_{\max }^{n}}^{n}
\end{array}\right]
$$

We can estimate the heat flux harmonics $\tilde{q}_{n}\left(t_{k}\right)$ without regularization by an ordinary least square method:

$$
\hat{\tilde{q}}_{n}=\left(S_{n}^{t} S_{n}\right)^{-1} S_{n}^{t} \hat{\tilde{\theta}}_{n}
$$

The return to time-space domain yields:

$$
q^{\prime \prime}\left(r, t_{k}\right)=\frac{2}{R^{2}} \sum_{n=0}^{n_{\max }} \frac{J_{0}\left(\alpha_{n} r_{t}\right)}{J_{0}^{2}\left(\alpha_{n} R\right)} \hat{\tilde{q}}_{n}\left(t_{k}\right)
$$

\subsection{Measurements of the liquid mass flux distributions}

A patternator, composed of a row of twelve tubes connected to individual sampling vessels, is specially designed in order to measure the distribution of the liquid mass flux for each nozzle. The diameter of each individual tube is $7.5 \mathrm{~mm}$, leading to a collection surface of $44.5 \mathrm{~mm}^{2}$. The distance between two consecutives tubes is twice the diameter tube value. The patternator is placed so that the top of the tubes are located at the same $Z$ elevation of the front face similarly to the PDA probe volume in the case of free sprays. The use of the 3D-traverse system allows moving the spray in order to scan the spray section in the $X-Y$ plane. The liquid mass flux is then 
measured during a given time, on the order of $180 \mathrm{~s}$ per measurement. Typically, the liquid mass flux distribution is described with a mesh having $11 * 11$ measurement points for each nozzle.

\section{ACQUISITION PROCEDURE AND DATA REDUCTION}

As mentioned in section 2., each experiment has a heating phase and a cooling one. For the heating phase, the inductor is placed as close as possible to the surface in order to ensure a quick heating. The heating phase is monitored by the IR camera and is stopped when the average rear surface temperature is about $800^{\circ} \mathrm{C}$. Then, the cooling of the disk can begin. For this second phase, both PDA system and IR camera are synchronized. The trigger output of the PDA processor is used in order to trigger the IR camera as acquisition and the spray operation (valves $\mathrm{A}$ and $\mathrm{B}$ ). The recording time $\Delta t_{r}$ depends on the cooling time, reached when the average surface temperature is equal to the initial liquid temperature $T_{l}=19^{\circ} \mathrm{C}$. As different liquid flow rates are used, $\Delta t_{r}$ varies from 20 up to $30 \mathrm{~s}$ according the nozzle. During the cooling phase, IR frames and PDA data are recorded on two separated computers.

The analysis of the results aims to correlate spatially the heat flux removed from the wall with the liquid mass flux and droplet properties distribution. But, the absence of a perfect symmetry in the liquid mass flux distribution (see Fig. 4) leads to an asymmetric and inhomogeneous cooling. Therefore, a data reduction is necessary for the further analysis. Basically, it consists in calculating an average value for each of the measured quantities, within an element of crown centered on the target (radius $r$, thickness $d r$ ). Thereby, all the averaged quantities depend only on one spatial variable $r$ (varying from $r=0$ up to $r=R$ ) and is invariant according the azimuth position on the surface.

\section{CHARACTERISTICS OF THE FREE SPRAYS}

Fig. 4a gives an example of the liquid mass flux distribution obtained with the nozzle 1 in the spray section located at $Z=250 \mathrm{~mm}$. It depicts clearly the non-uniformity of the liquid mass flux distribution. The evolution of the averaged liquid mass flux along a radius for all the considered nozzles is showed in Fig. $4 \mathrm{~b}$. Whatever the sprays, the liquid mass flux varies from about $2.5 \mathrm{up} 8 \mathrm{~kg} / \mathrm{m}^{2} / \mathrm{s}$. Close to the center, the nozzle 5 and the nozzle 2 have respectively the highest and the lowest liquid mass flux value. Towards the edge of the disk, all curves tend to merge and seem to increase slowly with $r$. Obviously, the liquid mass flux of the jet is relevant, but, the comparison with the case of nozzle 1 should be performed on the whole surface area of the disk. This will be discussed and presented in the section 7 .

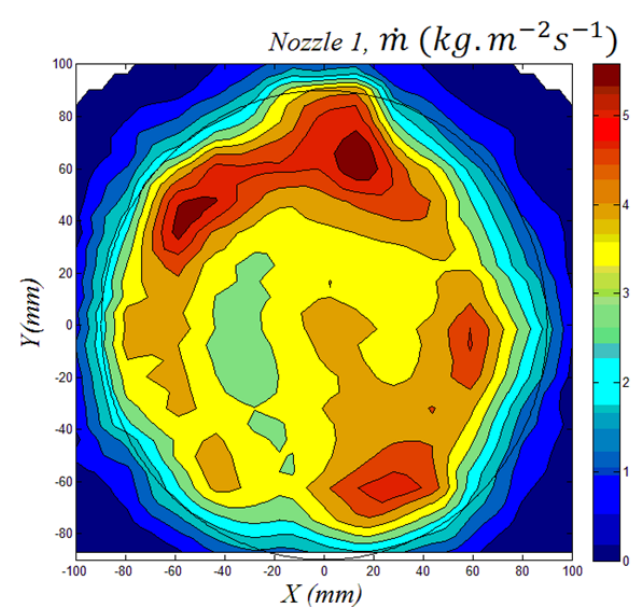

(a)

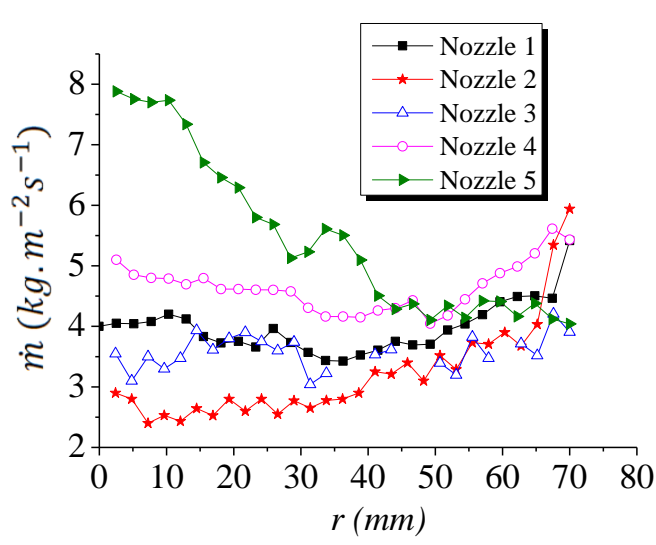

(b)

Fig. 4 Typical liquid mass flux distribution measured in a cross-section obtained with nozzle 1 (a) and along a radius for the five nozzles after data reduction (b). 
Fig. 5 presents the statistical properties of the droplets (derived from all the droplet size classes), obtained with the 2D-PDA system: mean values of the two velocity components, Sauter Mean Diameter (SMD) and mean Weber number based on SMD. The evolution of the $w$ velocity component (a), the $v$ velocity component (b), the SMD $d_{32}$ (c) and the mean Weber number $W e$ (d) are plotted along a radius. The Weber number is base on the SMD and the vertical velocity. It appears that the nozzles 2 and 3 have the lowest values of velocities and SMD and consequently of the Weber number. As observed in figure5(c), the dependence of the Weber number as a function of the radius remains low. As expected, nozzles 4 and 5 have the highest horizontal velocity $(v$ component) due their higher cone angles.

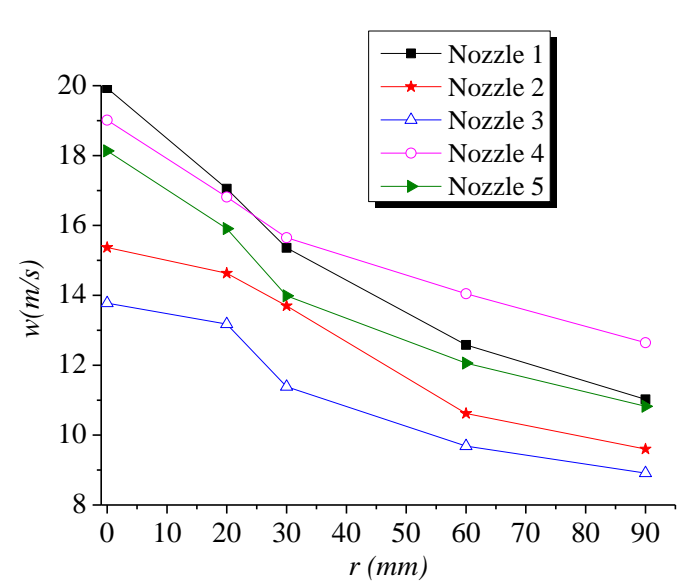

(a)

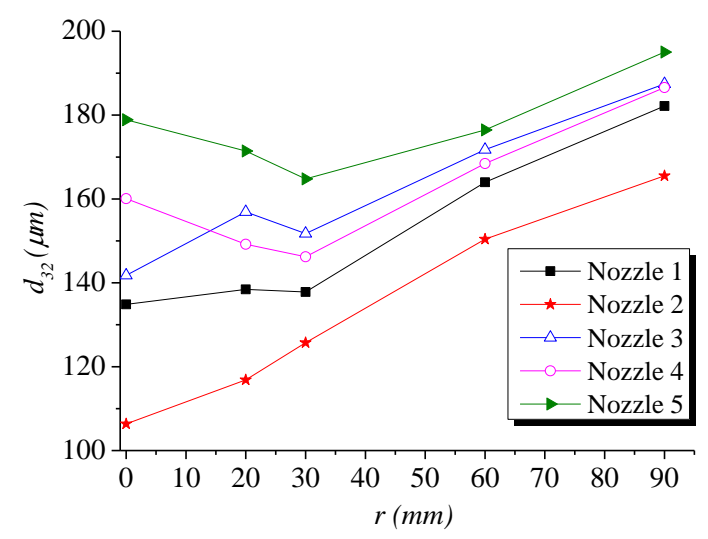

(b)

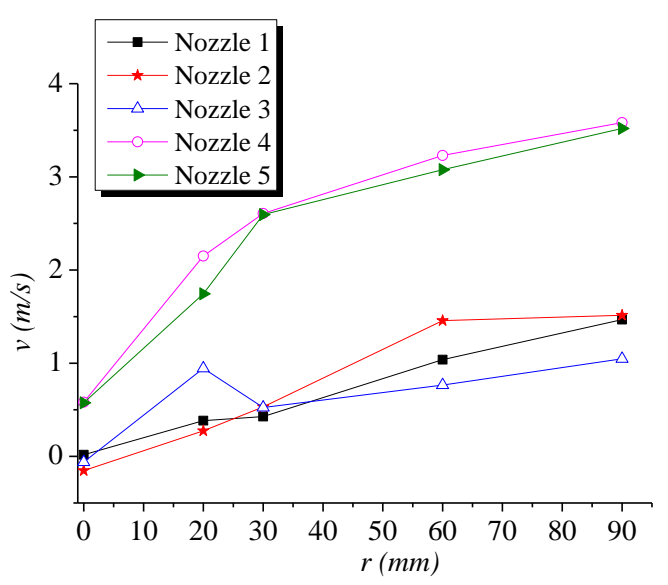

(b)

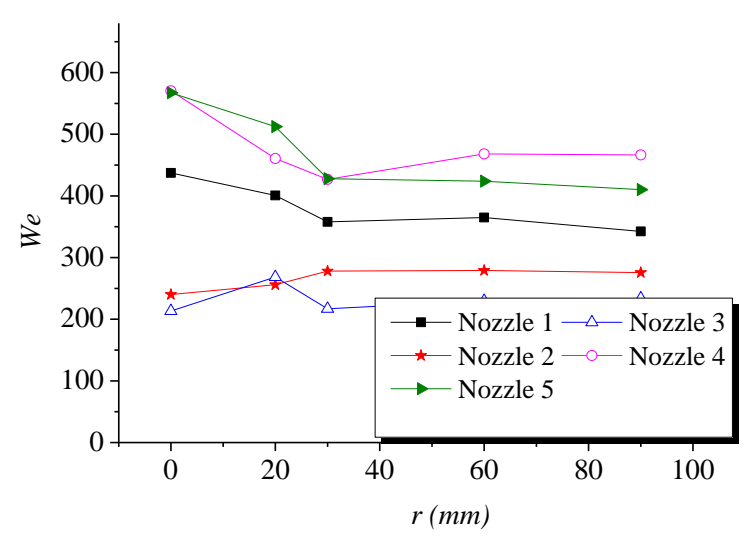

(c)

Fig. 5 Droplet statistical properties along a radius obtained from the PDA measurements after data reduction for the five nozzles: mean vertical velocities (a), mean horizontal velocity (b), SMD (c) and mean Weber number based on SMD (d).

\section{STUDY OF THE COOLING}

\subsection{Influence of the wall on the incident droplets properties}

To analyze the cooling characteristics of a heated surface, the incoming droplet properties are often measured in absence of the surface. However, the presence of the surface is likely to influence the trajectories of the droplets. This section aims to verify this assumption. The PDA results about the incoming droplets in the case of an impinging spray are compared with those obtained in the case of a free spray (without the disk). Fig. 6a depicts the incoming droplets size distribution in impinging conditions and in absence of the disc for nozzle 1 . Both are 
measured at $Z=240 \mathrm{~mm}$, i.e. $10 \mathrm{~mm}$ above the disk surface. Clearly, a significant difference can be observed: the pdf of the droplet size measured in the case of the impinging spray exhibits a shift towards larger droplets sizes compared to the case of the free spray. This can be potentially attributed to the deviation of the flowfield by the disk, resulting in a deviation of the small droplets $(d<50 \mu \mathrm{m})$ which follow the deviated flow due to their small Stokes number. Fig. 6b, describes the evolution of the horizontal velocity ( $v$ component) as a function of the droplet diameter. It tends to confirm this explanation: the horizontal velocity of the smallest incoming droplets increases widely in the case the impinging spray. It corresponds to the deviation of the smallest droplets towards the disk edges. Therefore, the effect of the surface to be cooled on a spray flow can modify significantly the droplet distribution of size and velocity in the impingement region.

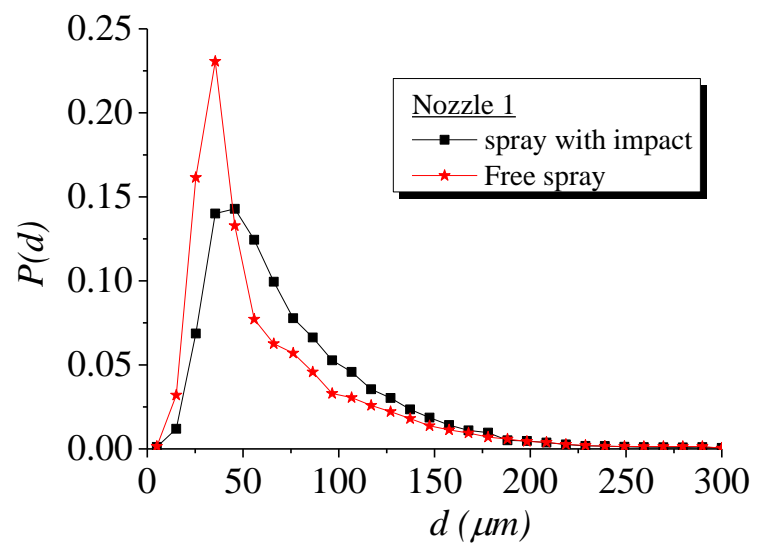

(a)

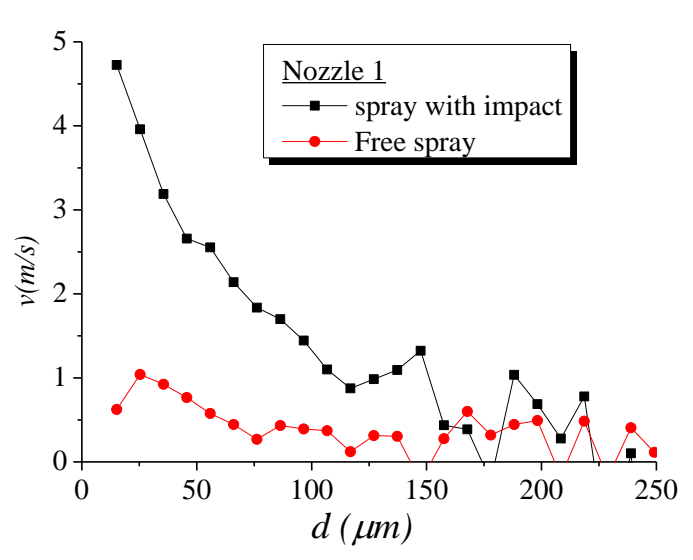

(b)

Fig. 6 Comparison of the incoming droplets parameters measured in the case of a free spray and in presence of the disk for nozzle 1: pdf of the size distributions (a) and distribution of the horizontal velocity as a function of the diameter (b).

\subsection{Investigation of characteristics of the impinging droplets}

This section is devoted to the study of the interaction of the droplets onto the heated wall. The following results are derived from PDA measurements recorded during the cooling phase, at a distance of $10 \mathrm{~mm}$ above the front face of the wall and at $X=Y=0$. . Fig. 7 describes typical size distributions of incoming and outcoming droplets for the nozzle 1, incoming droplets having a positive vertical velocity and outcoming droplets having a negative one. Even if outcoming detected droplets seems to be generally smaller than the outcoming one, both distribution are peaking at the same value $(d \approx 40 \mu \mathrm{m})$.

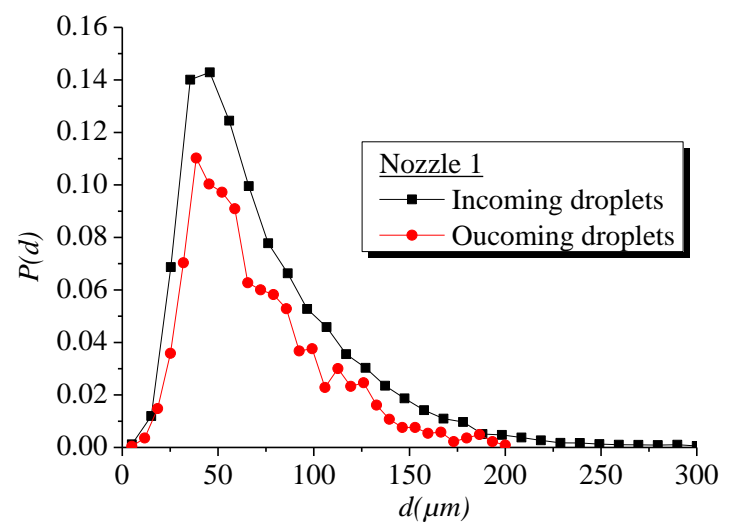

Fig. 7 Typical incoming and outcoming droplets size distribution

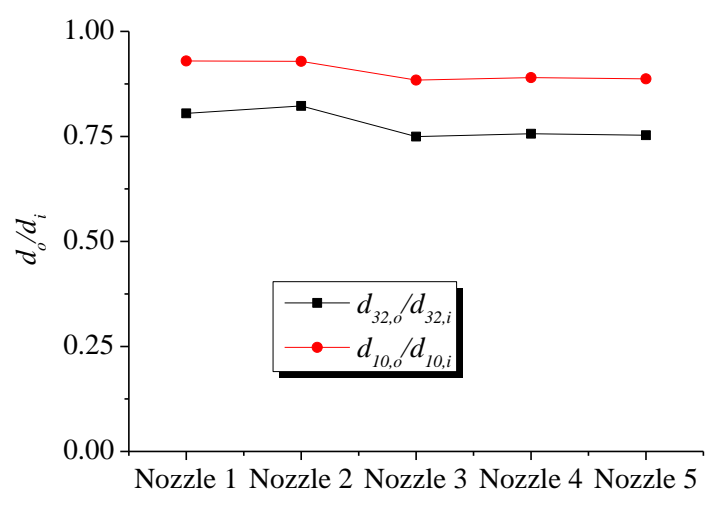

Fig. 8 Ratio of the outcoming Sauter mean diameter to the incoming Sauter diameter and ratio of the outcoming mean diameter to the incoming mean diameter, for the five nozzles. 
The ratio of the outcoming Sauter mean diameter $D_{32, o}$ to the incoming Sauter diameter $D_{32, i}$ for the five sprays is presented in Fig. 8 as well as the ratio for the mean diameter $\left(D_{10, d} D_{10, i}\right)$. It appears that these ratios are relatively close to one, especially for the mean diameter. Nevertheless, the outcoming droplets that the PDA device detected can be incoming droplet that rebounded and also incoming droplet that splashed. The Weber distributions of incoming droplets for the five sprays are depicted in Fig. 10. It shows that all distributions peak for a Weber number of about 100. Therefore, we can assume that the droplet splashing is surely the main phenomenon. Thereby, results of Fig. 7 and 8 can be related to the disintegrations by splashing of the biggest droplets in smaller one.

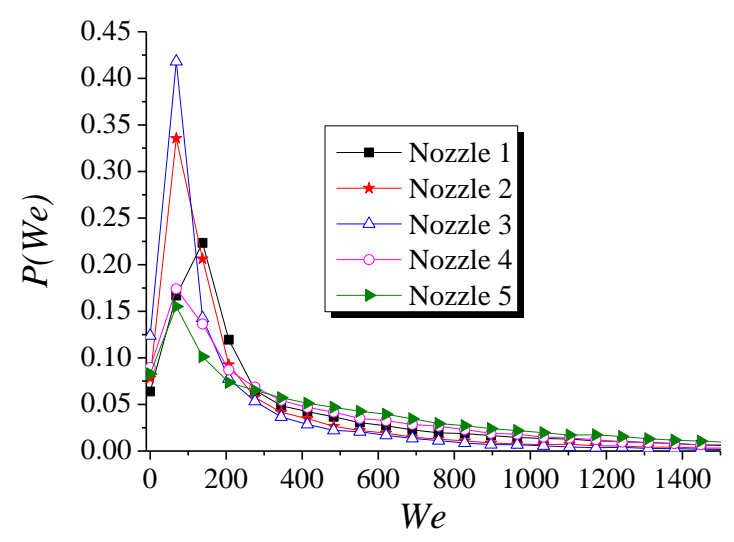

Fig. 9 Incoming droplet Weber distribution for the five studied nozzle

\subsection{Study of the heat transfers rate}

For numerical reasons, the IR images have not been post-processed up to $r=R$. Thus, all the following results are presented for a maximum radius value of $70 \mathrm{~mm}$.

Study of the heat flux removed from the wall - Fig. 10 depicts typical heat flux extracted by the nozzle 1 and 4 along a radius (horizontally) and as a function of the time (vertically). The colorbar is kept identical for useful comparison). The main comments are the following:

- For nozzle 1 and up to $t \approx 7 \mathrm{~s}$, the heat flux is almost spatially uniform. After, non homogeneous regions appear along the radius. For $0<r<30 \mathrm{~mm}$ at $t \approx 13 \mathrm{~s}$, we can observe the apparition of the Leidenfrost regime (the heat flux is minimum) before to reach the critical heat flux (CHF) at $\mathrm{t} \approx 18 \mathrm{~s}$. From $t \approx 20 \mathrm{~s}$, the heat flux decreasing (nucleate boiling regime) is again almost homogeneous throughout the radius.

- For nozzle 4 , the CHF is reached quickly $(t \approx 3 \mathrm{~s})$. Transition between wetting and non-wetting regime (Leidenfrots point) cannot be clearly identified. Before the CHF point, the heat flux presents strong spatial inhomogenities. Conversely, past the CHF point, the cooling rate is relatively homogeneous.

The boiling curves for the five sprays are presented in Fig. 11 and are plotted at two radius values: $r=2.5 \mathrm{~mm}$ (a), and $r=70 \mathrm{~mm}$ (b). At $r=2.5 \mathrm{~mm}$, the plots for nozzle 4 and 5 are clearly above the others. Indeed, at this position, nozzle 4 and 5 present the highest liquid mass flux value (Fig. 4b). When $r$ increases, the boiling curves corresponding to the different sprays tend to superimpose; this can be related to the fact that from $r \approx 35 \mathrm{~mm}$, the liquid mass flux for the five nozzles is similar. Moreover, for nozzle 1, 2 and 3 it is easy to observe that the Leidenfrost temperature tends to increase when $r$ increases. This observation is also directly correlated to the liquid mass flux which increases with $r$ (Fig. 4b). This is in well agreement with the observation of Al-Ahmadi and Yao [3]. 


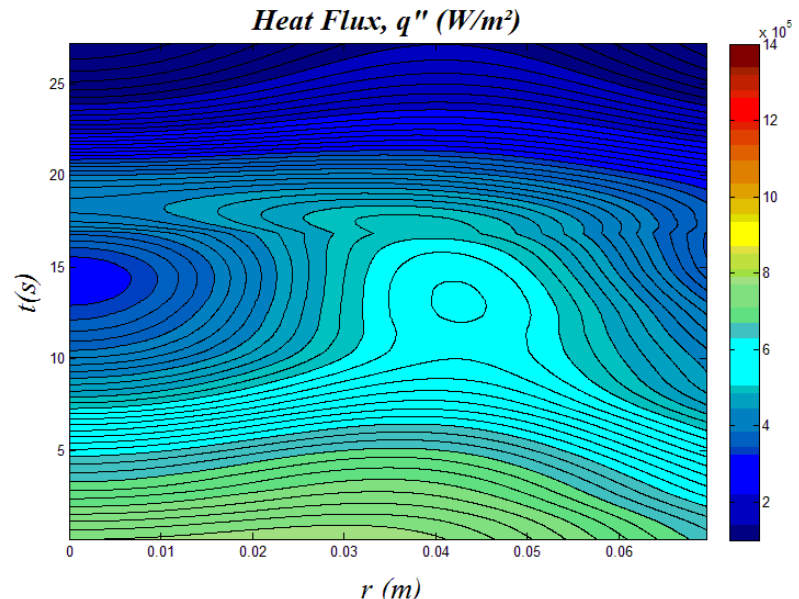

(a)

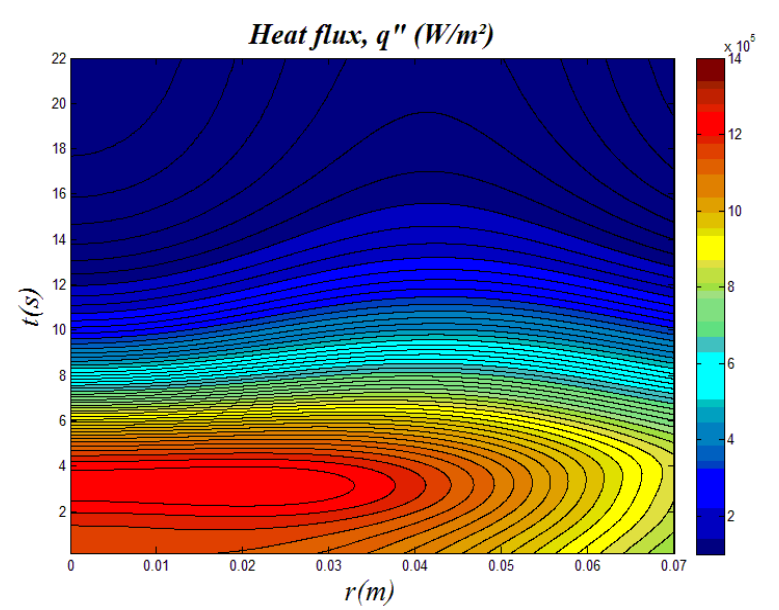

(b)

Fig. 10 Evolution of the heat flux extracted to the wall by the sprays along a radius and as a function of the time for nozzle 1 (a) and for nozzle 4 (b).

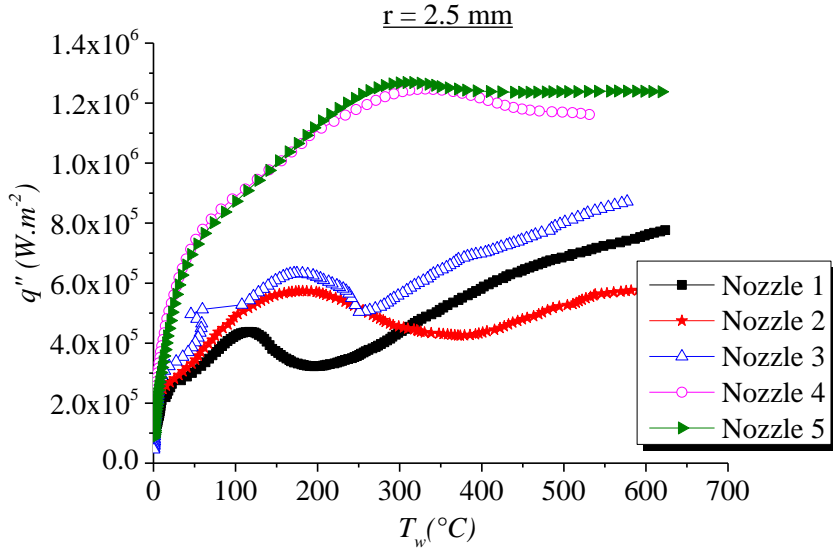

(a)

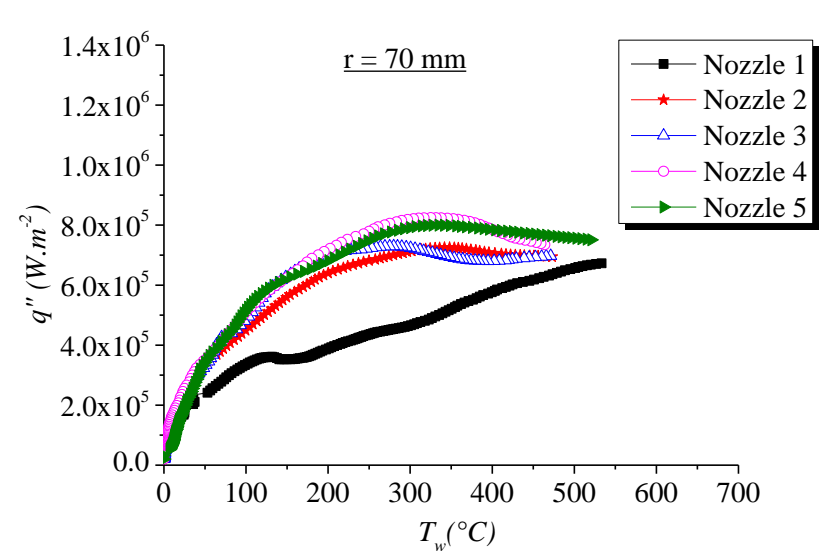

(b)

Fig. 11 Boiling curves of the five nozzles plotted at $X=2.5 \mathrm{~mm}$ (a) and $X=70 \mathrm{~mm}$ (b).

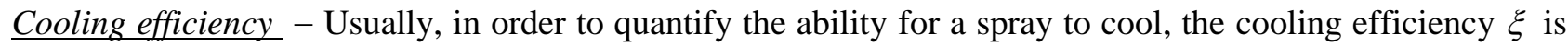
introduced:

$$
\zeta=\frac{q^{\prime \prime}}{\dot{m}\left[h_{v}+c_{p l}\left(T_{s a t}-T_{l}\right)+c_{p v}\left(T_{w}-T_{s a t}\right)\right]}
$$

It represents the amount of heat extracted by the spray divided by the total heat transfer which is required for complete evaporation of the liquid, which includes the power required to heat the liquid up to its saturation temperature and to heat the vapor up to the wall temperature. The evolution of the cooling efficiency along the radius is presented in Fig. 12 for the five sprays at a given time during the cooling when the wall temperature $T_{w}$ is $560^{\circ} \mathrm{C}$. In the central part of the plate, from $r=0$ up to $r \approx 40 \mathrm{~mm}$, it is observed that the nozzle 2 has the highest cooling efficiency $(\zeta \approx 11 \%)$ whereas the other nozzle presents relatively similar cooling efficiencies, on the order of $6 \%$. In the outer part of the plate (for $40<r<70 \mathrm{~mm}$ ), the cooling efficiency is the same regardless the nozzle used and decreases slowly with increasing the radial coordinate. These observations can be correlated with the liquid mass flux (Fig. 4b). In the central part, the nozzle has the lowest liquid mass flux and the highest cooling efficiency. In the second part, all nozzles have their liquid masse flux that increases and their cooling efficiency that decreases.

Therefore, it should be conclude that an increase of the liquid mass flux is correlated to a decrease of the cooling efficiency. In a previous study carried out by Yao and Cox [16], similar conclusions were found. These authors introduced the spray Weber number based on the SMD and the liquid mass flux: 


$$
W e_{s}=\frac{\dot{m}^{2} d_{32}}{\rho \sigma}
$$

The liquid mass flux is preferred because the direct effect of the droplet velocity on the cooling efficiency is not clearly established. Their work highlighted that the cooling efficiency decreases with the spray Weber number. However, it is expected that the wall temperature $T_{w}$ as well as the liquid temperature $T_{l}$ can also influence the effectiveness. Finally, based on experiments performed on several sprays, they proposed a correlation for the cooling efficiency, based on $W e_{s}, T_{l}$ and $T_{w}$ :

$$
\zeta=8 \times 10^{-7}\left[\frac{W e_{s} T_{s a t}}{T_{w}-T_{l}}\right]^{-0.62}+3.5 \times 10^{-7}\left[\frac{W e_{s} T_{\text {sat }}}{T_{w}-T_{l}}\right]^{-0.2}
$$

This correlation is valid over a wide range of operating conditions and is well adapted for those of the present study. Knowing the distribution of the liquid mass flux, the SMD (Fig. 4b and Fig. 5b respectively) and the wall temperature, the quantity $W e_{s} T_{s a l} /\left(T_{w^{-}}-T_{l}\right)$ can be derived, the initial liquid temperature being taken at $19^{\circ} \mathrm{C}$ (Table 1). Therefore, it is possible to compare the cooling efficiency obtained in the present study (eqn. (9)) with those obtained by Yao and Cox [16] (eqn. 11). The cooling efficiency from both present study and those of Yao and Cox [16] are plotted in Fig. 13 as a function of $W e_{s} T_{s a l} /\left(T_{w}-T_{l}\right)$ for the five nozzles and for a constant wall temperature of $560{ }^{\circ} \mathrm{C}$. As the wall temperature is fixed, the sole effect of the liquid mass flux can be observed. As expected, the cooling efficiency decreases with the liquid mass flux and is clearly above the values obtained by Yao and Cox [16]. The cooling efficiency corresponding to nozzle 2 is almost twice the values determined for the other nozzle.

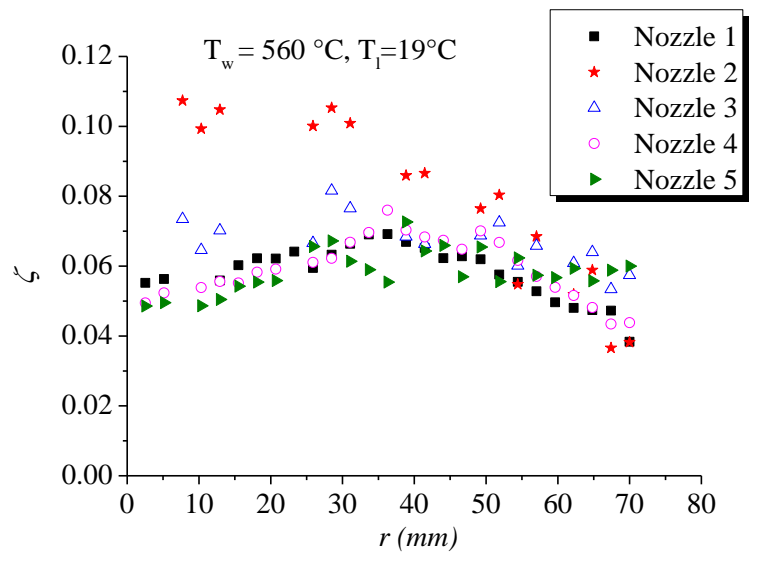

Fig. 12 Profiles of cooling efficiency for the five nozzles along a radius when the wall temperature is $560^{\circ} \mathrm{C}$.

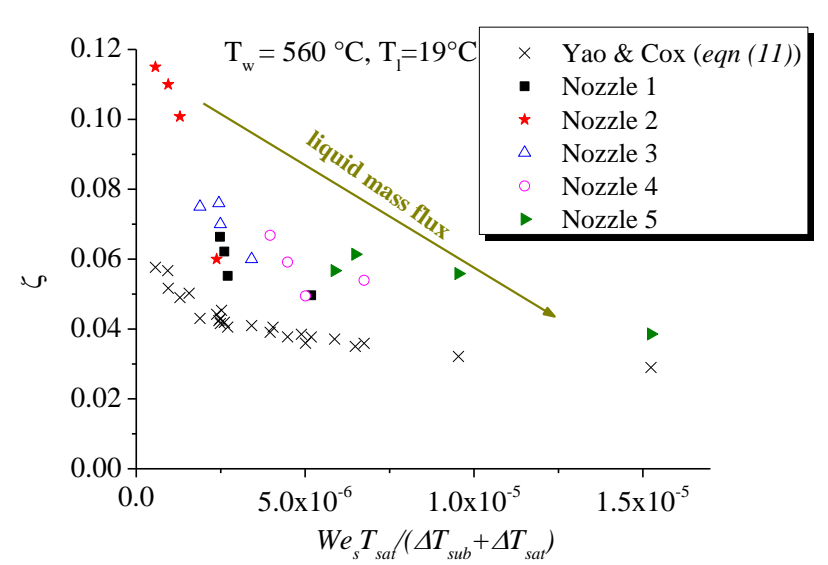

Fig. 13 Comparison of cooling efficiency obtained in the present study with the correlation of Yao\&Cox, when the wall temperature is $560^{\circ} \mathrm{C}$.

Fig. 14 depicts the cooling efficiency obtained for the five nozzles at two different wall temperatures. As in Fig. 13, the correlation of Yao \& Cox is slightly below of the value found in the present experiments. It is observed that the cooling efficiency decreases as the wall temperature increases; one potential explanation could be in relation with increase of vapor film thickness due to higher wall temperature, on other one could be related to homogeneous nucleate boiling inside the droplets leading to their disintegration. 


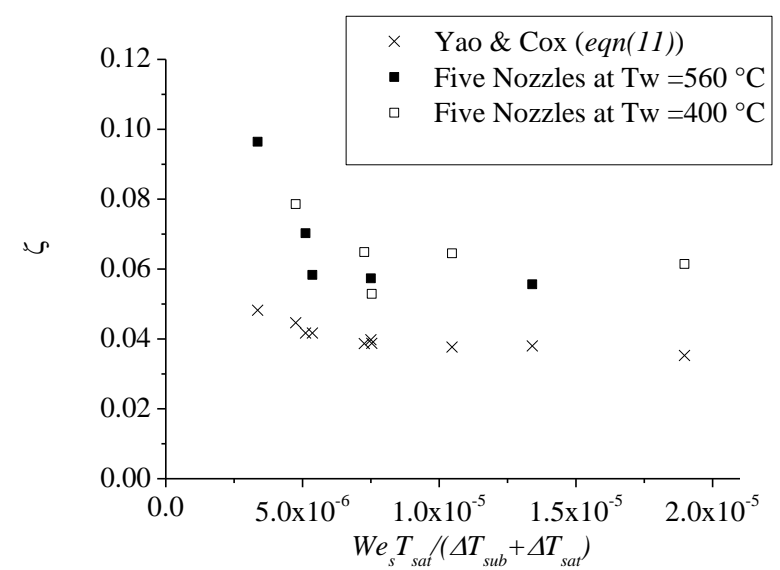

Fig. 14 Comparison of the experimental cooling efficiency obtained for 5 sprays and the correlation of Yao\&Cox, for two wall temperature values.

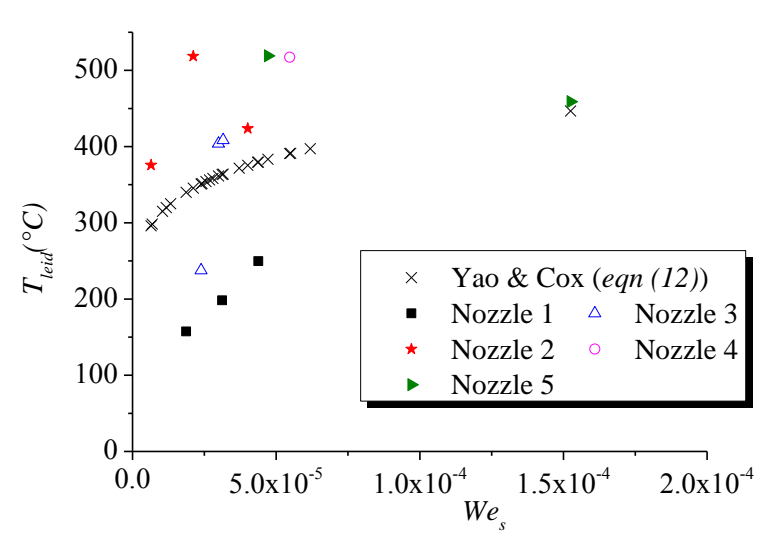

Fig. 15 Evolution of the Leidenfrost temperature as a function of the spray Weber number and comparison with the correlation of Yao \& Cox.

The Leidenfrost temperature $T_{\text {Leid }}$ was also investigated. The leidenfrost temperature can be determined using the boiling curves when the heat flux experiences a minimum value. This leidenfrost point is easier to detect for the lower liquid mass flux. This observation is often mentioned in the literature and is related to the absence of a stable boiling film. However, the Leidenfrost temperature tends generally to increase with the liquid mass flux [3]. Fig. 15 presents the evolution of the leidenfrost temperature as a function of the spray Weber number for the five nozzles. For each nozzle, the Leidenfrost temperature is obtained at several positions along the radius. It appears that $T_{\text {Leid }}$ increases with $W e_{s}$, i.e. with the liquid mass flux as mentioned just above. Yao \& Cox [16] suggested a correlation for $T_{\text {Leid }}$ :

$$
T_{\text {leid }}=1400 \mathrm{We} e_{s}^{0.13}
$$

This correlation is plotted in Fig. 15 and the best agreement is found with the experimental data for the highest liquid mass flux.

\section{COMPARISON BETWEEN THE LIQUID JET AND THE NOZZLE $\mathbf{N}^{\circ} 1$}

Fig. 16 depicts the heat flux extracted by the liquid jet along a radius and as a function of the time (the colorbar is the same as in Fig. 10). Here, the impact area of the jet has an extension up to $r=4.5 \mathrm{~mm}$. The diagonal band shows very well the advancement of the reweting front with a velocity of about $3 \mathrm{~mm} / \mathrm{s}$.

As expected, the cooling is widely faster than nozzle 1 and 4 (Fig. 10). For instance at $r=0$, the heat flux falls down from about $14 \times 10^{6} \mathrm{~W} / \mathrm{m}^{2}$ to $14 \times 10^{6} \mathrm{~W} / \mathrm{m}^{2}$ in only 2 seconds. Moreover, the heat flux distribution presents an important spatio-temporal inhomogeneity. Fig. 17 compares the boiling curve (black symbols) and the cooling efficiency (blue symbols) for the liquid jet and for nozzle 1. In order to make the two cases comparable, the heat flux of both liquid jet and nozzle 1 is integrated on the whole disk area and on the cooling duration (i.e. up to a final mean surface temperature of $T_{l}=19^{\circ} \mathrm{C}$ ). Therefore, $q$ " and $T_{w}$ in Fig. 17 are the heat flux and the wall temperature respectively averaged on the whole disk area (from $r=0$ up to $r=70 \mathrm{~mm}$ ). Even if the averaged heat flux for the liquid jet presents has strong oscillations (due to its spatiotemporal inhomogeneity), it is anyway greater than for the spray. On the other side, the spray has the greatest cooling efficiency. Indeed, the liquid mass flux of the liquid jet (based on the whole disk area) is about 7.5 $\mathrm{kg} / \mathrm{m}^{2} / \mathrm{s}$, i.e. almost the twice of the spray. These first results demonstrate two main drawbacks of the cooling using liquid jet: strong inhomogeneity and low efficiency. 


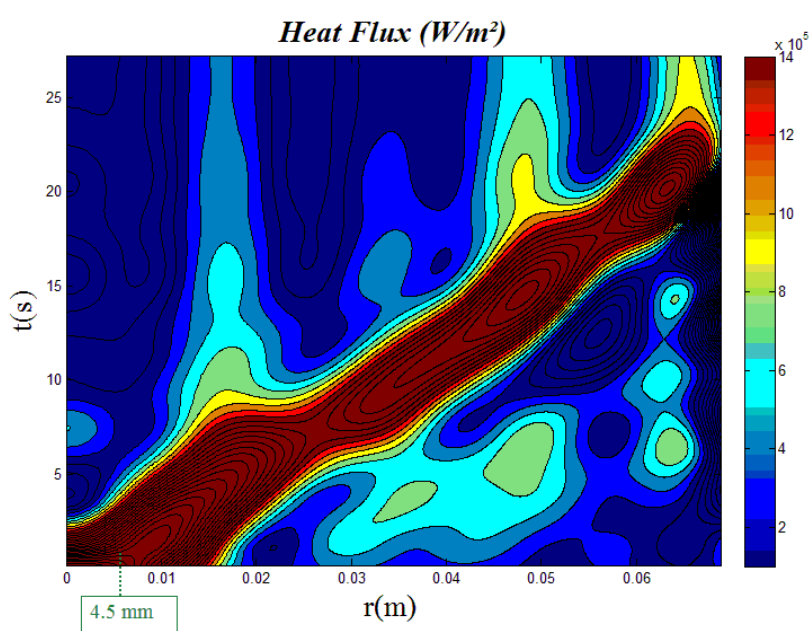

Fig. 16 Evolution of the heat flux extracted from the wall by the liquid jet along a radius and as a function of the time

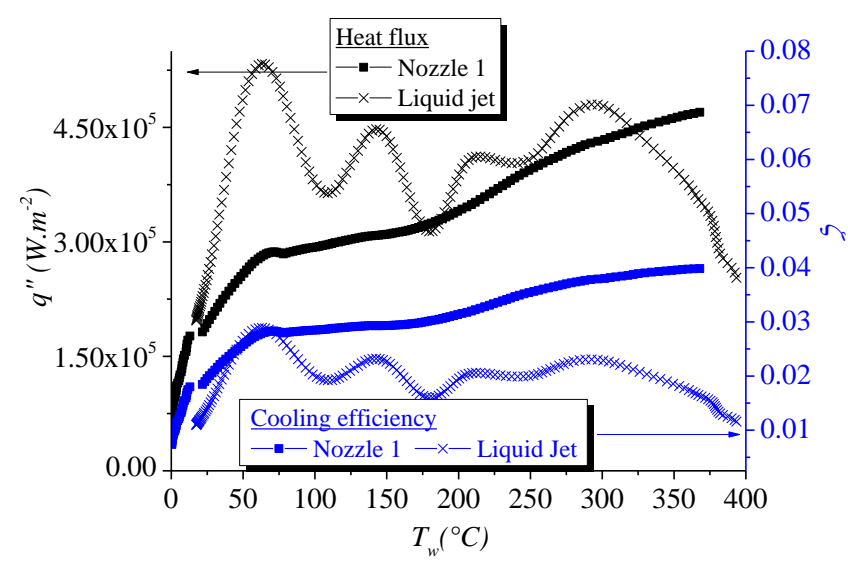

Fig. 17 Comparison of the Boiling curve and cooling efficiency for the liquid jet and for nozzle 1 .

\section{CONCLUSIONS}

An experimental set-up was developed in order to investigate water cooling of high-temperature surfaces under semi-industrial conditions. The cooling by a liquid jet and several polydisperse full cone sprays are compared. The wall, a $175 \mathrm{~mm}$ diameter nickel disk, is heated by an induction device up to $800^{\circ} \mathrm{C}$ before to be quenched. The heat flux was estimated with infrared thermography combined with an inverse conduction method synchronized a phase-Doppler system. In first, the effect of the presence of the wall on the motion of the incoming droplets was highlighted. The trajectories of the smallest droplets, which behave as passive tracers, are deviated by the plate, which reduce their impingement probability on the heated target. The comparison between the statistics of the incoming and outcoming droplets shows a slight decrease of the mean Sauter diameter and is attributed to the disintegration of the largest droplets to smaller one.

When spray cooling is considered, the cooling efficiency decreases with the sprayed liquid mass flux and the Leidenfrost temperature increases with the wall temperature, which is in qualitative agreement with other studies of the literature. The comparison of the liquid jet with a spray show that even if higher heat flux can be removed with the liquid jet, their use leads to strong spatiotemporal inhomogeneities and low cooling efficiency.

Future works will be devoted to investigate the case of sprays having higher liquid mass flux. In addition, high speed camera vizualistion will be performed in order to describe more thoroughly the interactions of the spray with the heated plate and to identify the different hydrodynamic regime (rebound, splashing, and film deposition).

\section{ACKNOWLEDGMENT}

This work has been supported by the French National Agency (ANR) in the frame of the research program IDHEAS (ANR NT09 432160).

\section{NOMENCLATURE}

$\begin{array}{llllll}\text { We } & \text { We number } & (-) & C_{p} & \text { specific capacity } & (\mathrm{J} / \mathrm{Kg} \cdot \mathrm{K}) \\ \operatorname{Re} & \text { Reynolds number } & (-) & d & \text { droplet diameter } & (\mathrm{m})\end{array}$




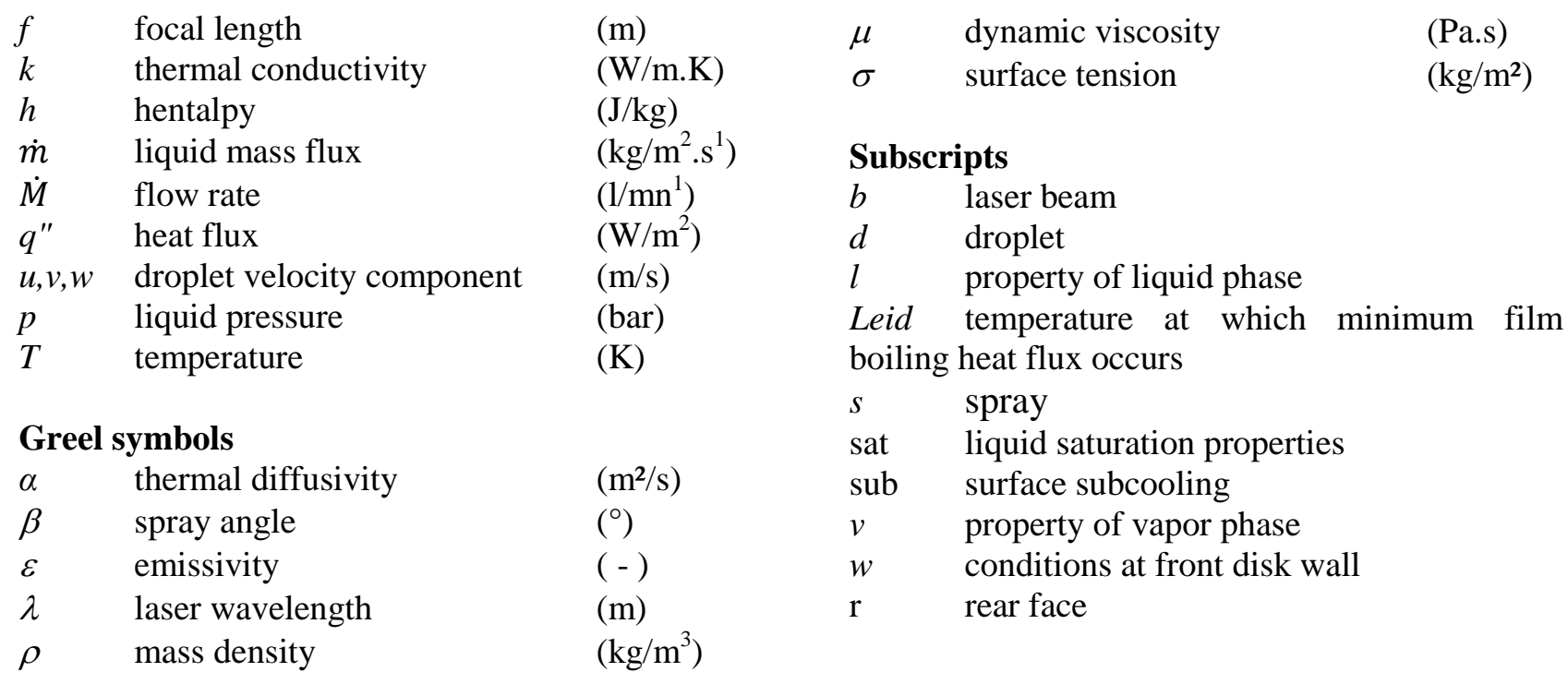

\section{REFERENCES}

[1] Choi K.J., Yao S.C.,"Heat transfer mechanisms of horizontally impacting sprays,” Int. J. Heat Mass Transf., 30(2), pp. 12911296, (1987). Journal Paper

[2] Deb S., Yao S.C., "Analysis on film boiling heat transfer of impacting sprays," Int. J. Heat Mass Transf., 32(11), pp. 20992112, (1987). Journal Paper

[3] Al-Ahmadi H.M., Yao, S.C., "Spray cooling of high temperature metals using high mass flux industrial nozzles," Exp. Heat Transf., 21, pp. 38-51, (2008). Journal Paper

[4] Cox T., Heat transfer experiments and general correlation for sprays of very large droplets, Ph.D. Thesis, Carnegie Mellon University, (1998). Dissertation

[5] Gaugler R.E., Experimental investigation of spray cooling of high temperature surfaces, Ph.D. Thesis, Carnegie Mellon University, (1966). Dissertation

[6] Hoogendoorn C.J., Valentine W.S. "Leidenfrost temperature and heat transfer coefficients for water sprays impinging o,n a hot surface," Proc. of 5th Int. Heat Trans. Conf., vol. 4, pp. 135-138, (1974). Conference Proceedings

[7] Cox T.L., Yao S.C., "Heat transfer of sprays of large water drops impinging on high temperature surfaces," J. Heat Transf., 121(2), pp. 446-450, (1999). Journal Paper

[8] Jia W., Qiu H.H. "Experimental investigation of droplet dynamics and heat transfer in spray cooling," Exp. Thermal and Fluids Sc., 27, pp. 829-838(2003). Journal Paper

[9] Chen R.H., Chow L.C., Navedo J.E., "Effects of sprays characteristics on critical heat flux in subcooled water sprays cooling," Int. J. Heat Mass Transf., 45, pp. 4033-4043, (2002). Journal Paper

[10] Gradeck M., Ouattara J.A., Rémy B, Maillet D., "Solution of an inverse problem in the hankel space - infrared thermography applied to estimation of a transient cooling flux," Exp. Thermal and Fluids Sc., 36, pp. 56-64(2012). Journal Paper

[11] Dunand P., Castanet G., Gradeck M., Lemoine F. and Maillet D., "Heat transfer of droplets impinging onto a wall above the leidenfrost temperature," Compte Rendus Mécanique., 341 (1-2), pp. $75-87$ (2013). Journal Paper

[12] Puschmann F., Specht E. and Schmidt J., "Measurements of sprays cooling heat transfer using an infrared technique in combination with the Phase Doppler technique and a patternator," Int. J. Heat and Tech. ., 19, pp. 51-56, (2001). Journal Paper

[13] Ouattara A., Gradeck M., Maillet D., Remy B., Lebouché M. "Solution of IHCP estimation of a nonuniform source using an inverse heat conduction method based on an analytical solution," Proc. of Eurotherm., (2008). Conference Proceedings

[14] Gradeck M., Ouattara A., Maillet D., Gardin P., Lebouché M. "Heat transfer associated to a hot surface quenched by a jet oil in water emulsion," Exp. Thermal and Fluid Sc., 35 (5), pp. 841-847 (2011). Journal Paper

[15] Maillet D., André S., Barsale J., Degiovanni A., Moyne C., Thermal Quadrupoles - Solving the heat equation through integral transforms, Chisester: Wiley, (2000). Edited Book

[16] Yao S. C., Cox T.L. "A general heat transfer correlation for impacting water sprays on high-temperature surfaces," Exp. Heat Transf., 15, pp. 207-219, (2002). Journal Paper 